\title{
Compositional Dependence of Curie Temperature and Magnetic Entropy Change in the Amorphous Tb-Co Ribbons
}

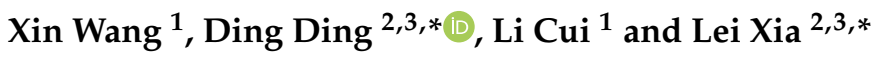 \\ 1 College of Engineering, Shanghai Polytechnic University, Shanghai 201209, China; \\ wangxin2020@126.com (X.W.); cuili@sspu.edu.cn (L.C.) \\ 2 Institute of Materials, Shanghai University, Shanghai 200072, China \\ 3 Center for Advanced Microanalysis, Shanghai University, Shanghai 200444, China \\ * Correspondence: d.ding@shu.edu.cn (D.D.); xialei@shu.edu.cn (L.X.); Tel.: +86-021-66135067 (D.D. \& L.X.)
}

check for updates

Citation: Wang, X.; Ding, D.; Cui, L.; Xia, L. Compositional Dependence of Curie Temperature and Magnetic Entropy Change in the Amorphous Tb-Co Ribbons. Materials 2021, 14, 1002. https://doi.org/10.3390/ ma14041002

Academic Editor: Victor M. Prida

Received: 15 January 2021

Accepted: 17 February 2021

Published: 20 February 2021

Publisher's Note: MDPI stays neutral with regard to jurisdictional claims in published maps and institutional affiliations.

Copyright: (c) 2021 by the authors. Licensee MDPI, Basel, Switzerland. This article is an open access article distributed under the terms and conditions of the Creative Commons Attribution (CC BY) license (https:/ / creativecommons.org/licenses/by/ $4.0 /)$.

\begin{abstract}
The Curie temperature $\left(T_{c}\right)$ and magnetic entropy change $\left(-\Delta S_{m}\right)$, and their relationship to the alloy composition of $\mathrm{Tb}$-Co metallic glasses, were studied systematically in this paper. It was found that, in contrast to the situation in amorphous Gd-Co ribbons, the dependence of $\mathrm{Tc}$ on $\mathrm{Tb}$ content and the maximum $-\Delta S_{m}$ vs. $T_{c}-2 / 3$ plots in Tb-Co binary amorphous alloys do not follow a linear relationship, both of which are supposed to be closely related to the non-linear compositional dependence of $\mathrm{Tb}-\mathrm{Co}$ interaction due to the existence of orbital momentum in $\mathrm{Tb}$.
\end{abstract}

Keywords: amorphous materials; curie temperature; magnetic entropy change

\section{Introduction}

In recent years, with the increasing demands for reducing energy consumption and the mitigating global warming, new refrigeration technologies have been intensively investigated. Amongst these innovative refrigeration technologies, magnetic refrigeration (MR) technology has been extensively concerned since it is free contributing to the depletion of the ozone layer and due to its long-service life, superior to the that of traditional vapor compression refrigeration technology. Therefore, experts in the related research fields are paying more and more attention to the development of novel magnetocaloric materials in the last two decades because the efficiency of the magnetic refrigerator is determined by the magnetocaloric properties of its magnetic refrigerant [1-5].

Amorphous magnetocaloric alloys, as an important category of magnetic refrigerant, show potential applications from the perspective of magnetic refrigerators because they possess a rather broad "hillside" of magnetic entropy change $\left(-\Delta S_{m}\right)$ and a low but adequate maximum $-\Delta S_{m}\left(-\Delta S_{m}{ }^{\text {peak }}\right)$, which results in an ultrahigh refrigeration capacity (RC) [5-27]. This makes it possible to design and manufacture metallic glass composites with a flattened $-\Delta S_{m}$ peak within a tailorable temperature span because magnetic refrigerant with a flattened $-\Delta S_{m}$ peak within the cold end and the hot end of a refrigerator is expected to be optimal in an Ericsson cycle [6-9].

In the preliminary works, metallic glasses consisting of rare earth (RE) elements and transition metals (TM) elements, especially the Gd-TM-based amorphous alloys, have demonstrated excellent magnetocaloric properties [8-19]. However, RE-TM-based amorphous materials containing other rare earth (Tb, Dy, etc.) metals usually exhibit spinglass-like behaviors and high coercivity at low temperature [19-27]. The hard magnetic properties make the magnetocaloric behaviors irreversible and thus deteriorate the application perspective of these metallic glasses. Therefore, it is necessary to systematically observe the magnetic and the magnetocaloric properties of the Tb/Dy-TM binary metallic glasses, which may be helpful to understand the relationship between alloy composition and the magnetic properties, the origin of coercivity and their influences on the magnetocaloric effect of these metallic glasses. 
In this paper, the magnetic properties and magnetocaloric effect, including the Curie temperature $\left(T_{\mathcal{c}}\right)$, coercivity, spin freezing temperature $\left(T_{f}\right)$ and the $-\Delta S_{m}$ of the binary $\mathrm{Tb}-\mathrm{Co}$ amorphous alloys were measured. Based on these results, the dependence of Curie temperature on the composition of the alloys and the relationship between the maximum $-\Delta S_{m}$ and the Curie temperature of the glassy samples were established, and the mechanism involved was investigated.

\section{Materials and Methods}

Sample synthesis: $\mathrm{Tb}$ and Co pure metals with a purity higher than 99.9 at.\% were mixed together according to the stoichiometric compositions of $\mathrm{Tb}_{\mathrm{x}} \mathrm{Co}_{100-\mathrm{x}}(\mathrm{x}=45,50,55$, $60,62.5)$ and were arc-melted, respectively, into the shape of ingots in the presence of a Ti getter under an Ar atmosphere. Ribbons of each alloy were manufactured by means of melt-spinning method under the protection of an argon atmosphere. The thickness of the ribbons is $\sim 40 \mu \mathrm{m}$ in average.

Structural characterization: The disordered structure of the $\mathrm{Tb}_{\mathrm{x}} \mathrm{Co}_{100-\mathrm{x}}$ ribbons was confirmed by a Rigaku X-ray diffractometer (model D/max-rC) with $\mathrm{Cu} K_{\alpha}$ source.

Magnetic measurements: the $T_{c}$ and $T_{f}$ of the ribbons were obtained from the magnetization vs. temperature $(M-T)$ curves measured under a magnetic field of $0.03 \mathrm{~T}$ (Tesla) after a cooling under a zero field (ZFC) and a cooling under a magnetic field (FC) of $0.03 \mathrm{~T}$. Saturation magnetization $\left(M_{S}\right)$ and the coercivity of the ribbons were obtained from the hysteresis loops measured under a field of $5 \mathrm{~T}$. The plots of $-\Delta S_{m}$ vs. temperature $\left(\left(-\Delta S_{m}\right)-T\right.$ curves) were constructed according to the Maxwell equation from the isothermal magnetization $(M-H)$ curves measured at various temperatures under $5 \mathrm{~T}$. The $M-T$ curves, hysteresis loops and $M-H$ curves were measured on a vibrating sample magnetometer module of a quantum design PPMS Evercool II system. Measurement precision is less than $5 \times 10^{-6} \mathrm{emu} / \mathrm{T}($ Tesla $)$.

\section{Results}

Figure 1 illustrates the X-ray diffraction (XRD) patterns of the as-spun $\mathrm{Tb}_{\mathrm{x}} \mathrm{Co}_{100-x}$ $(x=45,50,55,60,62.5)$ ribbons. Only broad humps representing the first diffuse halo and the absence of visible crystalline peaks indicate the formation of a fully amorphous phase in each ribbon.

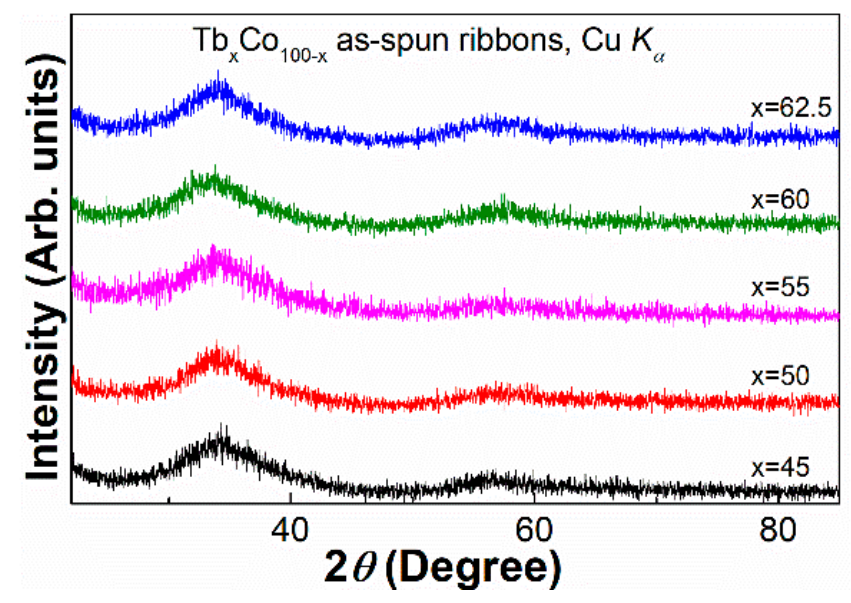

Figure 1. XRD patterns of the $\mathrm{Tb}_{\mathrm{x}} \mathrm{Co}_{100-\mathrm{x}}(\mathrm{x}=45,50,55,60,62.5)$ as-spun ribbons.

Figure 2a displays the FC $M-T$ curves of the $\mathrm{Tb}_{\mathrm{x}} \mathrm{Co}_{100-\mathrm{x}}(\mathrm{x}=45,50,55,60,62.5)$ glassy samples measured under a field of $0.03 \mathrm{~T}$. By taking the derivation of the $M-T$ curves, we can obtain the Curie temperature of the glassy samples as follows: $170 \mathrm{~K}$ for $\mathrm{Tb}_{45} \mathrm{Co}_{55}$, $130 \mathrm{~K}$ for $\mathrm{Tb}_{50} \mathrm{Co}_{50}, 105 \mathrm{~K}$ for $\mathrm{Tb}_{55} \mathrm{Co}_{45}, 97 \mathrm{~K}$ for $\mathrm{Tb}_{60} \mathrm{Co}_{40}$ and $92 \mathrm{~K}$ for $\mathrm{Tb}_{62.5} \mathrm{Co}_{37.5}$ [28], as summarized in Table 1. The variation of the Curie temperature with the composition of the $\mathrm{Tb}_{\mathrm{x}} \mathrm{Co}_{100-\mathrm{x}}$ glassy samples, and the $\mathrm{Dy}_{\mathrm{x}} \mathrm{Co}_{100-\mathrm{x}}$ as well as $\mathrm{Gd}_{\mathrm{x}} \mathrm{Co}_{100-\mathrm{x}}$ binary metallic 
glasses for comparison purpose [11,23], are plotted, respectively, in Figure 2b. Along with the increase in RE content, the Curie temperature of the three kinds of RE-Co binary metallic glasses decreases monotonously. However, one can find that the compositional dependence of $T_{\mathcal{c}}$ follows a linear relationship in Gd-Co binary alloys, which in contrast, is non-linear in $\mathrm{Tb}-\mathrm{Co}$ and Dy-Co binary alloys.
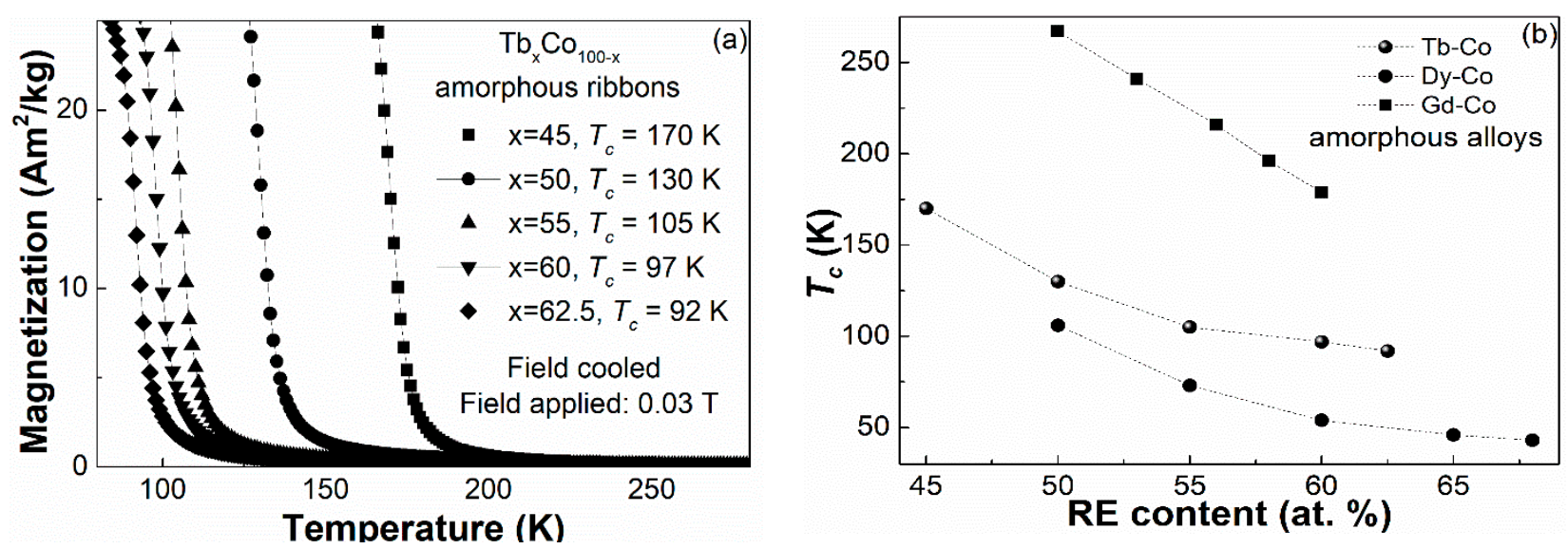

Figure 2. (a) FC $M-T$ curves of the $\mathrm{Tb}_{\mathrm{x}} \mathrm{Co}_{100-\mathrm{x}}(\mathrm{x}=45,50,55,60,62.5)$ amorphous ribbons; (b) the relationship between the $T_{c}$ and the RE element content in the $\mathrm{Tb}_{\mathrm{x}} \mathrm{Co}_{100-\mathrm{x}}, \mathrm{Dy}_{\mathrm{x}} \mathrm{Co}_{100-\mathrm{x}}$ and $\mathrm{Gd}_{\mathrm{x}} \mathrm{Co}_{100-\mathrm{x}}$ amorphous alloys.

Table 1. The Curie temperature $\left(T_{c}\right)$, spin freezing temperature $\left(T_{f}\right)$ and $-\Delta S_{m}{ }^{\text {peak }}$ under various magnetic fields of the $\mathrm{Tb}_{\mathrm{x}} \mathrm{Co}_{100-\mathrm{x}}$ amorphous ribbons.

\begin{tabular}{|c|c|c|c|c|c|c|c|c|c|}
\hline \multirow{2}{*}{$\begin{array}{c}\mathrm{Tb}_{\mathrm{x}} \mathrm{Co}_{100-\mathrm{x}} \\
\text { Ribbons }\end{array}$} & \multirow{2}{*}{$T_{c}(\mathrm{~K})$} & \multirow{2}{*}{$T_{f}(\mathrm{~K})$} & \multicolumn{6}{|c|}{$-\Delta S_{m}^{\text {peak }}\left(\mathrm{J} \mathrm{K}^{-1} \mathrm{~kg}^{-1}\right)$} & \multirow{2}{*}{ Ref. } \\
\hline & & & $1 \mathrm{~T}$ & $1.5 \mathrm{~T}$ & $2 \mathrm{~T}$ & $3 \mathrm{~T}$ & $4 \mathrm{~T}$ & $5 \mathrm{~T}$ & \\
\hline$x=45$ & 170 & 139 & 1.45 & 2.04 & 2.58 & 3.56 & 4.46 & 5.31 & \multirow{4}{*}{ Present work } \\
\hline$x=50$ & 130 & 113 & 1.94 & 2.76 & 3.52 & 4.90 & 6.15 & 7.30 & \\
\hline$x=55$ & 105 & 95 & 2.52 & 3.54 & 4.46 & 6.10 & 7.54 & 8.84 & \\
\hline$x=60$ & 97 & 88 & 2.67 & 3.75 & 4.71 & 6.39 & 7.86 & 9.18 & \\
\hline$x=62.5$ & 92 & 78 & 2.77 & 3.86 & 4.83 & 6.51 & 7.97 & 9.27 & [28] \\
\hline
\end{tabular}

In order to reveal the mechanism for the dependence of $T_{\mathcal{C}}$ on composition in these RE-Co binary metallic glasses, it is necessary to study the interactions between atoms in these metallic glasses, including the Co-Co (direct) interaction, the RE-RE (indirect) interaction and RE-Co (indirect) interaction. If the variation of Curie temperature with the composition of the RE-Co binary glassy alloys is only induced by the RE-RE interaction, the relationship between the Curie temperature and the RE content in the RE-Co binary metallic glasses agrees well with the RKKY (Ruderman-Kittel-Kasuya-Yosida) indirect interaction model, that is, $T_{c}$ will have a linear relationship with the $G$ factor, which is a physical quantity simply related to the mole fraction of the RE element in the alloy system that contains merely one type of RE atoms $[17,26]$. For amorphous alloys containing only one RE element, the $\mathrm{G}$ factor is proportional to the molar fraction of the RE atoms. Therefore, from the viewpoint of $4 \mathrm{f}-4 \mathrm{f}$ indirect interaction, the compositional dependence of $\mathrm{Tc}$ in $\mathrm{Tb}-\mathrm{Co}$ amorphous alloys should be linear. However, in addition to the $4 \mathrm{f}-4 \mathrm{f}$ indirect interaction between the RE-RE atoms, there are two other kinds of interactions in RE-TM-based amorphous alloys: $3 \mathrm{~d}-3 \mathrm{~d}$ direct interaction between the TM-TM atoms and the $3 \mathrm{~d}-4 \mathrm{f}$ indirect interaction between the RE-TM atoms. The influence of the $3 \mathrm{~d}-3 \mathrm{~d}$ direct interaction on the Curie temperature in the RE-TM-based amorphous alloys is supposed to be similar to that of the $4 \mathrm{f}-4 \mathrm{f}$ indirect interaction. This is understandable because there is only $(100 \%) 3 \mathrm{~d}-3 \mathrm{~d}$ direct interaction in a pure TM metal, and no $(0 \%) 3 \mathrm{~d}-3 \mathrm{~d}$ direct interaction in alloys free of TM elements. The contribution of the $3 \mathrm{~d}-3 \mathrm{~d}$ direct interaction 
is proportional to the molar fraction of the Co element in $\mathrm{Tb}-\mathrm{Co}$ amorphous alloys and the compositional dependence of Tc in Tb-Co amorphous alloys is still linear from the viewpoint of $3 \mathrm{~d}-3 \mathrm{~d}$ direct interaction. However, the effect of $3 \mathrm{~d}-4 \mathrm{f}$ indirect interaction on the Curie temperature in RE-TM-based amorphous alloys is more complicated [23]. On the other hand, the direct interaction between Co atoms is largely influenced by the surrounding environment of a $\mathrm{Co}$ atom, which means that the addition of the large-size $\mathrm{RE}$ atoms (e.g., Gd, Tb, Dy...) give rise to the expansion of the distance between Co atoms and thus weaken the interactions between Co atoms. In other words, if the variation of Curie temperature with the composition of the RE-Co binary glassy alloys is considered to be only induced by the $\mathrm{Co}-\mathrm{Co}$ direct interaction, the Curie temperature of the RE-Co binary metallic glasses will decrease with the decreasing content of $\mathrm{Co}$. The dependence of $T_{c}$ on the Co-Co interaction probably resembles the case of the RE-RE interaction, which indicates the linear relationship between $T_{c}$ and Co content when only $\mathrm{Co}_{\mathrm{O}}-\mathrm{Co}_{\mathrm{interaction}}$ is considered. The assumption can be ascertained in the binary $\mathrm{Gd}-\mathrm{Co}$ metallic glasses [11]. Unlike other RE metals such as $\mathrm{Tb}$ and $\mathrm{Dy}, \mathrm{Gd}$ has no orbital momentum due to its stable half-full $4 f$ shell, and thus the interaction among Gd-Co atoms can generally be ignored. As such, the Curie temperature of the Gd-Co metallic glass system ultimately depends on the co-effect of the $\mathrm{Co}-\mathrm{Co}$ direct interaction and $\mathrm{Gd}-\mathrm{Gd}$ indirect interaction. Considering that the $T_{c}$ exhibits a linear relationship with the composition in the Gd-Co metallic glasses, as shown in Figure $2 b$, and the concentration of Gd element and $T_{c}$ are linearly related according to the RKKY model, the relationship between Co concentration and $T_{c}$ induced by the Co-Co interaction should also be linear. It is reported that the $T_{\mathcal{c}}$ variation induced by the Gd-Gd indirect interaction is nearly equal to the variation of the $T_{c}$ induced by the direct interaction between $\mathrm{Ni}-\mathrm{Ni}$ atoms, which makes the Curie temperature remains constant near $123 \mathrm{~K}$ in the $\mathrm{Gd}-\mathrm{Ni}$ binary metallic glasses [12]. In contrast, the increase in $\mathrm{Gd}$ content in $\mathrm{Gd}-\mathrm{Co}$ metallic glasses, that is, the decrease in Co concentration, makes the Curie temperature decrease linearly from 267 to $179 \mathrm{~K}$ because the direct interaction between Co atoms is much stronger than that of the $\mathrm{Ni}$ atoms.

The compositional dependence of the Curie temperature in the binary $\mathrm{Tb}-\mathrm{Co}$ and Dy-Co amorphous alloy systems; however, is more complicated because of the existence of RE-Co interactions [23]. For the binary $\mathrm{Tb}-\mathrm{Co}$ metallic glasses in the present work, the $\mathrm{Tb}-\mathrm{Co}$ interaction is zero either in pure $\mathrm{Tb}$ or in pure $\mathrm{Co}$, but exists in $\mathrm{Tb}-\mathrm{Co}$ compounds, changing with the composition of the alloy and reaching a maximum value at a certain composition. As a result, the relationship between $T_{c}$ and $\mathrm{Tb}$ content in the $\mathrm{Tb}-\mathrm{Co}$ metallic glass system will not be the linear relationship in $\mathrm{Gd}-\mathrm{Co}$ alloys. The parabolic-like nonlinear curve exhibited in $\mathrm{Tb}-\mathrm{Co}$ binary amorphous alloys is somewhat similar to the one in Dy-Co binary alloys, indicating the similar variation trend of $T_{\mathcal{c}}$ induced by the RE-Co interaction in the binary $\mathrm{Dy}-\mathrm{Co}$ and $\mathrm{Tb}-\mathrm{Co}$ amorphous alloys.

In our preliminary work, the Gd-Co amorphous alloys are soft magnetic with almost zero hysteresis because the stable half full electron arrangement in the $4 f$ shell of Gd atom does not produce orbital momentum and thus $\mathrm{Gd}$ has a relatively small magnetocrystalline anisotropy. In contrast, the unstable electronic arrangement of the $4 f$ shell in the $\mathrm{Tb}$ or Dy atom gives rise to the existence of orbital momentum and produces a large magneto-crystalline anisotropy, which is expected to result in a relatively high coercivity at low temperature in $\mathrm{Tb}-\mathrm{Co}$ and $\mathrm{Dy}-\mathrm{Co}$ amorphous alloys. As shown in Figure $3 \mathrm{a}$, the $\mathrm{Tb}_{55} \mathrm{Co}_{45}$ amorphous ribbon is hard magnetic with a coercivity of $\sim 326 \mathrm{kA} / \mathrm{m}$ at $20 \mathrm{~K}$, soft magnetic at $95 \mathrm{~K}$ and paramagnetic at $160 \mathrm{~K}$. The high coercivity at $20 \mathrm{~K}$ is due to the random magnetic anisotropy (RAM) which exists in Tb-based amorphous system [20-22], which will lead to the preferential orientation between the magnetic moments, destroy the macroscopic effective anisotropy directions of the magnetic order and thereby produce the hysteresis. 

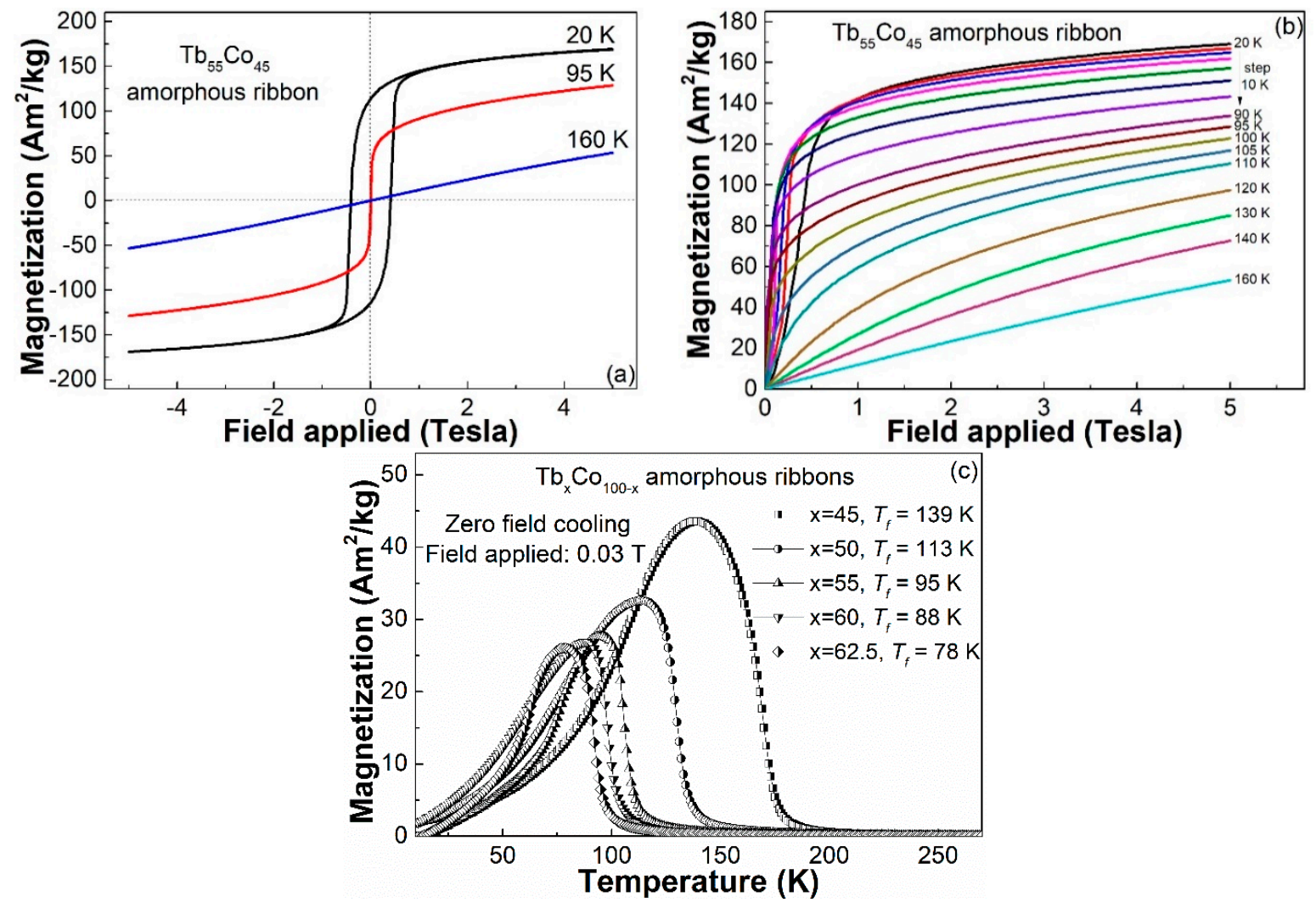

Figure 3. (a) The hysteresis loops and (b) the isothermal $M-H$ curves of the $\mathrm{Tb}_{55} \mathrm{Co}_{45}$ amorphous ribbon measured at different temperature under a magnetic field of $5 \mathrm{~T}$; (c) zero field (ZFC) $M-T$ curves of the $\mathrm{Tb}_{\mathrm{x}} \mathrm{Co}_{100-\mathrm{x}}(\mathrm{x}=45,50,55,60$, 62.5) amorphous ribbons.

In order to reveal the magnetocaloric properties of $\mathrm{Tb}-\mathrm{Co}$ binary metallic glass and explore the mechanism of the magnetic behaviors involved in a more intensive way, it is necessary to measure the isothermal magnetization curves at various temperatures ranging from a very low temperature of $20 \mathrm{~K}$ to a temperature of $160 \mathrm{~K}$ above the $T_{c}$. To prevent the effect of magnetization history on the $M-H$ curve at low temperature, the glassy ribbon was heat treated to eliminate residual magnetism during the measurement process. As shown in Figure 3b, the initial magnetization obviously increases with the increasing temperature from 20 to $90 \mathrm{~K}$ within a low range of magnetic field before saturation magnetization, which indicates the spin glass behavior of the $\mathrm{Tb}_{55} \mathrm{Co}_{45}$ metallic glasses [19-27]. The spin glass behaviors of the amorphous $\mathrm{Tb}_{\mathrm{x}} \mathrm{Co}_{100-\mathrm{x}}(\mathrm{x}=45,50,55,60,62.5)$ samples are also illustrated in Figure $3 \mathrm{c}$ by their ZFC $M-T$ curves. The spin freezing temperatures of these samples, as listed in Table 1, can be obtained from their ZFC $M-T$ curves.

According to the isothermal $M-H$ curves of the $\mathrm{Tb}_{\mathrm{x}} \mathrm{Co}_{100-\mathrm{x}}(\mathrm{x}=45,50,55,60,62.5)$ metallic glasses, the $-\Delta S_{m}$ vs. temperature under various magnetic fields can be obtained. Unfortunately, the spin freezing behavior and the high coercivity at low temperature obviously deteriorate the magnetocaloric properties of these alloys at temperatures below their spin freezing temperature, even decrease the $-\Delta S_{m}$ value to below zero at $20 \mathrm{~K}$. Therefore, we only study the magnetocaloric behaviors of the reversible part above the $T_{f}$. The $-\Delta S_{m}$ vs. temperature plots of the $\mathrm{Tb}_{\mathrm{x}} \mathrm{Co}_{100-\mathrm{x}}$ amorphous samples under the fields of $1.5 \mathrm{~T}$ and $5 \mathrm{~T}$ are demonstrated in Figure $4 \mathrm{a}$. The $-\Delta S_{m}{ }^{\text {peak }}$ of the $\mathrm{Tb}_{\mathrm{x}} \mathrm{Co}_{100-\mathrm{x}}$ metallic glasses increases with the increasing $\mathrm{Tb}$ content but decrease with the increasing $T_{c}$. The $-\Delta S_{m}$ peak values of the $\mathrm{Tb}_{\mathrm{x}} \mathrm{Co}_{100-\mathrm{x}}$ glassy samples under $1,1.5,2,3,4$ and $5 \mathrm{~T}$ are summarized in Table 1 . The $-\Delta S_{m}{ }^{\text {peak }}$ values of the $\mathrm{Tb}_{62.5} \mathrm{Co}_{37.5}$ amorphous alloy are much higher than those of the $\mathrm{TbCo}$ amorphous ribbons, which is most likely related to the higher magnetic moment of a $\mathrm{Tb}_{62.5} \mathrm{Co}_{37.5}$ amorphous alloy due to its high $\mathrm{Tb}$ concentration and 
the high magnetic moment of the Tb3+ ions $(\sim 9.72 \mu \mathrm{B})$ [28]. Considering the potential application perspective the linear $-\Delta S_{m}{ }^{\text {peak }} \propto T_{c}{ }^{-2 / 3}$ relationship in Gd-based amorphous alloys $[10,11,17,29]$, we constructed the $-\Delta S_{m}{ }^{\text {peak }}-T_{c}{ }^{-2 / 3}$ plots of $T_{\mathrm{x}} \mathrm{Co}_{100-\mathrm{x}}$ glassy ribbons obtained from the $\left(-\Delta S_{m}\right)-T$ plots under $5 \mathrm{~T}$, as shown in Figure $4 \mathrm{~b}$. Unlike the linear relationship between the $-\Delta S_{m}{ }^{\text {peak }}-T_{\mathcal{c}}{ }^{-2 / 3}$ plots in the binary Gd-Co glassy alloys, as also shown in Figure $4 \mathrm{~b}$ for comparison purposes, the relationship between $-\Delta S_{m}{ }^{\text {peak }}$ and $T_{c}{ }^{-2 / 3}$ in the $\mathrm{Tb}-\mathrm{Co}$ binary amorphous samples is more like a para-curve than a linear relationship. The non-linear change of the $-\Delta S_{m}{ }^{\text {peak }}$ and $T_{c}{ }^{-2 / 3}$ is also considered to be related to the non-linear relationship between the $\mathrm{Tb}$ concentration and $\mathrm{Tb}-\mathrm{Co}$ interaction in the $\mathrm{Tb}-\mathrm{Co}$ binary metallic glasses.
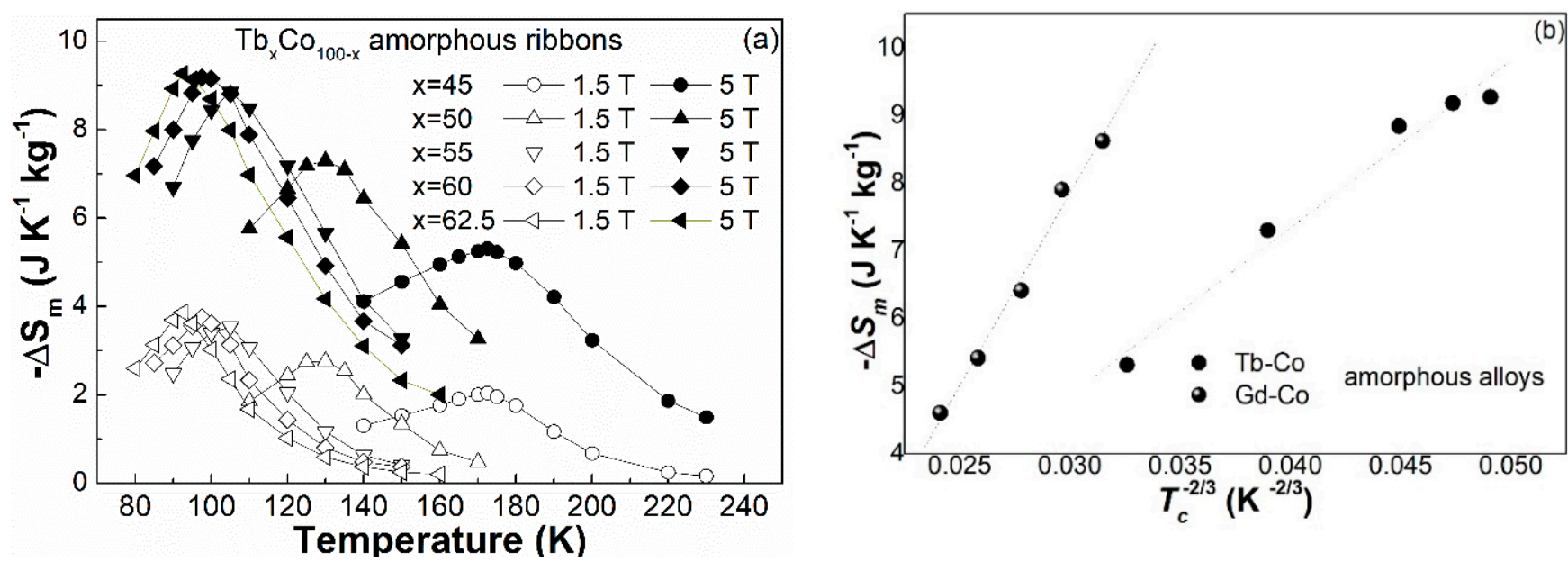

Figure 4. (a) The $\left(-\Delta S_{m}\right)-T$ curves of the $\mathrm{Tb}_{\mathrm{x}} \mathrm{Co}_{100-\mathrm{x}}(\mathrm{x}=45,50,55,60,62.5)$ amorphous ribbons under the magnetic field of $1.5 \mathrm{~T}$ and $5 \mathrm{~T} ;(\mathbf{b})$ the linear fittings of $T_{c}{ }^{-2 / 3}$ vs. $-\Delta S_{m}$ peak plots for the Gd-Co and Tb-Co amorphous alloys.

\section{Conclusions}

In summary, the compositional dependence of $T_{c}$ and $-\Delta S_{m}$ of the amorphous $\mathrm{Tb}_{\mathrm{x}} \mathrm{Co}_{100-\mathrm{x}}(\mathrm{x}=45,50,55,60,62.5)$ alloys, and the mechanism involved, were investigated in this paper. The magnetic properties and magnetocaloric effect of the binary $\mathrm{Tb}-\mathrm{Co}$ amorphous alloys were measured systematically. $T_{c}$ of the $\mathrm{Tb}-\mathrm{Co}$ metallic glasses were obtained from their FC M-T curves and the dependence of $T_{c}$ on the composition of the alloys was constructed. The spin-glass behaviors were observed in the isothermal $M-H$ curves at low temperature and the ZFC $M-T$ curves of the Tb-Co glassy alloys. To prevent the deterioration of the magnetocaloric properties by spin freezing behaviors, the $\left(-\Delta S_{m}\right)-T$ curves of the $\mathrm{Tb}_{\mathrm{x}} \mathrm{Co}_{100-\mathrm{x}}$ glassy alloys were established above the spin freezing temperature. Based on these results, the $-\Delta S_{m}{ }^{\text {peak }}$ vs. $T_{c}{ }^{-2 / 3}$ plots for the Tb-Co systems were obtained. It can be discovered that the compositional dependence of $T_{c}$ and the $-\Delta S_{m}{ }^{p e a k}$ vs. $T_{c}{ }^{-2 / 3}$ plots in $\mathrm{Tb}-\mathrm{Co}$ binary metallic glasses does not follow a linear relationship compared with the Gd-Co binary metallic glasses, which is mostly due to the non-linear compositional dependence of $\mathrm{Tb}-\mathrm{Co}$ interaction due to the existence of orbital momentum in $\mathrm{Tb}$.

Author Contributions: Measurement and date analysis, L.C. and X.W.; data analysis and investigation, L.X.; investigation, writing-review and editing, D.D. All authors have read and agreed to the published version of the manuscript.

Funding: The work described in this paper was supported by the National Natural Science Foundation of China (Grant Nos. 52071196, 51871139, 51671119 and 51675323). Shanghai Natural Science Foundation Project (No.20ZR1421000). Materials Science and Engineering Discipline of Shanghai Polytechnic University (XXKZD1601). Open project of China Key Laboratory(19AZ02). Shanghai Polytechnic University 2021 Youth Academic Backbone Training Project (EGD21QD17).

Institutional Review Board Statement: Not applicable. 
Informed Consent Statement: Not applicable.

Data Availability Statement: The data reported in this article are available on request from the Corresponding author.

Acknowledgments: This research was technical support by Center for Advanced Microanalysis.

Conflicts of Interest: The authors declared that they have no conflicts of interest to this work. We declare that we do not have any commercial or associative interest that represents a conflict of interest in connection with the work submitted. We confirm that the manuscript has been read and approved by all named authors and that there are no other persons who satisfied the criteria for authorship but are not listed. We further confirm that the order of authors listed in the manuscript has been approved by all of us. We confirm that we have given due consideration to the protection of intellectual property associated with this work and that there are no impediments to publication, including the timing of publication, with respect to intellectual property. In so doing we confirm that we have followed the regulations of our institutions concerning intellectual property. We understand that the Corresponding Author is the sole contact for the Editorial process (including Editorial Manager and direct communications with the office). He/she is responsible for communicating with the other authors about progress, submissions of revisions and final approval of proofs. We confirm that we have provided a current, correct email address which is accessible by the Corresponding Author and which has been configured to accept email from Materials.

\section{References}

1. De Oliveira, N.A.; von Ranke, P.J. Theoretical aspects of the magnetocaloric effect. Phys. Rep. 2010, 489, 89. [CrossRef]

2. Tishin, A.M.; Spichkin, Y.I. The magnetocaloric effect and its applications. Inst. Phys. Bristol. 2003. [CrossRef]

3. Franco, V.; Blázquez, J.S.; Ipus, J.J.; Law, J.Y.; Moreno-Ramírez, L.M.; Conde, A. Magnetocaloric effect: From materials research to refrigeration devices. Prog. Mater. Sci. 2018, 93, 112-232. [CrossRef]

4. Gschneidner, K.A.; Pecharsky, V.K. Magnetocaloric materials. Annu. Rev. Mater. Sci. 2000, 30, 387-429. [CrossRef]

5. Chaudhary, V.; Chen, X.; Ramanujan, R.V. Iron and manganese based magnetocaloric materials for near room temperature thermal management. Prog. Mater. Sci. 2019, 100, 64-98. [CrossRef]

6. Lai, J.W.; Zheng, Z.G.; Zhong, X.C.; Franco, V.; Montemayor, R.; Liu, Z.W.; Zeng, D.C. Table-like magnetocaloric effect of $\mathrm{Fe}_{88-\mathrm{x}} \mathrm{Nd}_{\mathrm{x}} \mathrm{Cr}_{8} \mathrm{~B}_{4}$ composite materials. J. Magn. Magn. Mater. 2015, 390, 87. [CrossRef]

7. Chen, L.S.; Zhang, J.Z.; Wen, L.; Yu, P.; Xia, L. Outstanding magnetocaloric effect of $\mathrm{Fe}_{88-\mathrm{x}} \mathrm{Zr}_{8} \mathrm{~B}_{4} \mathrm{Sm}_{\mathrm{x}}(\mathrm{x}=0$, 1, 2, 3) amorphous alloys. Sci. China Phys. Mech. Astro. 2018, 61, 056121. [CrossRef]

8. Ma, L.Y.; Gan, L.H.; Chan, K.C.; Ding, D.; Xia, L. Achieving a table-like magnetic entropy change across the ice point of water with tailorable temperature range in Gd-Co-based amorphous hybrids. J. Alloy. Compd. 2017, 723, 197. [CrossRef]

9. Liu, G.L.; Zhao, D.Q.; Bai, H.Y.; Wang, W.H.; Pan, M.X. Room temperature table-like magnetocaloric effect in amorphous $\mathrm{Gd}_{50} \mathrm{Co}_{45} \mathrm{Fe}_{5}$ ribbon. J. Phys. D Appl. Phys. 2016, 49, 055004. [CrossRef]

10. Tang, B.Z.; Xie, H.X.; Li, D.M.; Xia, L.; Yu, P. Microstructure and its effect on magnetic and magnetocaloric properties of the $\mathrm{Co}_{50} \mathrm{Gd}_{50-\mathrm{x}} \mathrm{Fe}_{\mathrm{x}}$ glassy ribbons. J. Non-Cryst. Solids 2020, 533, 119935. [CrossRef]

11. Wu, C.; Ding, D.; Xia, L.; Chan, K.C. Achieving tailorable magneto-caloric effect in the Gd-Co binary amorphous alloys. AIP Adv. 2016, 6, 035302. [CrossRef]

12. Tang, B.Z.; Huang, L.W.; Song, M.N.; Ding, D.; Wang, X.; Xia, L. Compositional dependence of magnetic and magnetocaloric properties of the Gd-Ni binary amorphous alloys. J. Non-Cryst. Solids 2019, 522, 119589. [CrossRef]

13. Xia, L.; Chan, K.C.; Tang, M.B.; Dong, Y.D. Achieving a large adiabatic temperature rise of $\mathrm{Gd}_{55} \mathrm{Co}_{25} \mathrm{Al}_{20}$ bulk metallic glass by minor Zn addition. J. Mater. Sci. 2015, 50, 1333-1337. [CrossRef]

14. Yu, P.; Zhang, N.Z.; Cui, Y.T.; Wen, L.; Zeng, Z.Y.; Xia, L. Achieving an enhanced magneto-caloric effect by melt spinning a $\mathrm{Gd}_{55} \mathrm{Co}_{25} \mathrm{Al}_{20}$ bulk metallic glass into amorphous ribbons. J. Alloy. Compd. 2016, 655, 353-356. [CrossRef]

15. Fu, H.; Zou, M. Magnetic and magnetocaloric properties of ternary Gd-Co-Al bulk metallic glasses. J. Alloy. Compd. 2011, 509, 4613-4616. [CrossRef]

16. Zheng, Z.G.; Zhong, X.C.; Su, K.P.; Yu, H.Y.; Liu, Z.W.; Zeng, D.C. Magnetic properties and large magnetocaloric effects in amorphous Gd-Al-Fe alloys for magnetic refrigeration. Sci. China Phys. Mech. Astro. 2011, 54, 1267-1270. [CrossRef]

17. Zhang, H.Y.; Li, R.; Zhang, L.L.; Zhang, T. Tunable magnetic and magnetocaloric properties in heavy rare-earth based metallic glasses through the substitution of similar elements. J. Appl. Phys. 2014, 115, 133903. [CrossRef]

18. Fang, Y.K.; Lai, C.H.; Hsieh, C.C.; Zhao, X.G.; Chang, H.W.; Chang, W.C.; Li, W. Magnetocaloric effect of the Gd-LRE-Al-(Co, Fe) (LRE=La, Ce, Pr, Nd) glassy ribbons in the intermediate temperature. J. Phys. Conf. Ser. 2011, 266, 012002. [CrossRef]

19. Luo, Q.; Wang, W.H. Magnetocaloric effect in rare earth-based bulk metallic glasses. J. Alloy. Compd. 2010, 495, 209. [CrossRef]

20. Du, J.; Zheng, Q.; Bruck, E.; Buschow, K.H.J.; Cui, W.B.; Feng, W.J.; Zhang, Z.D. Spin-glass behavior and magnetocaloric effect in Tb-based bulk metallic glass. J. Magn. Magn. Mater. 2009, 321, 413-417. [CrossRef] 
21. Luo, Q.; Schwarz, B.; Mattern, N.; Eckert, J. Giant irreversible positive to large reversible negative magnetic entropy change evolution in Tb-based bulk metallic glass. Phys. Rev. B 2010, 82, 024204. [CrossRef]

22. Speliotis, T.; Niarchos, D. Extraordinary magnetization of amorphous TbDyFe films. Microelectron. Eng. 2013, 112, 183. [CrossRef]

23. Ma, L.Y.; Tang, B.Z.; Chan, K.C.; Zhao, L.; Tang, M.B.; Ding, D.; Xia, L. Formability and magnetic properties of Dy-Co binary amorphous alloys. AIP Adv. 2018, 8, 075215. [CrossRef]

24. Xia, L.; Chan, K.C.; Ding, D.; Zhao, L.; Tang, B.Z. Magnetic properties and magnetostriction of a binary Dy50 $\mathrm{Co}_{50}$ amorphous alloy. J. Non-Cryst. Solids 2018, 493, 29-32. [CrossRef]

25. Luo, Q.; Schwarz, B.; Mattern, N.; Eckert, J. Irreversible and reversible magnetic entropy change in a Dy-based bulk metallic glass. Intermetallics 2012, 30, 76-79. [CrossRef]

26. Huo, J.T.; Huo, L.H.; Li, J.W.; Men, H.; Wang, X.M.; Inoue, A.; Chang, C.T.; Wang, J.Q.; Li, R.W. High-entropy bulk metallic glasses as promising magnetic refrigerants. J. Appl. Phys. 2015, 117, 073902. [CrossRef]

27. Huo, J.T.; Zhao, D.Q.; Bai, H.Y.; Axinte, E.; Wang, W.H. Giant magnetocaloric effect in Tm-based bulk metallic glasses. J. Non-Cryst. Solids 2013, 359, 1-4. [CrossRef]

28. Tang, B.Z.; Guo, D.Q.; Xia, L.; Ding, D.; Chan, K.C. Magnetoelastic and magnetocaloric properties of $\mathrm{Tb}_{62.5} \mathrm{Co}_{37.5}$ amorphous alloy. J. Alloy. Compd. 2017, 728, 747-751. [CrossRef]

29. Bloe, J.H.; Amaral, J.S.; Pereira, A.M.; Amaral, V.S.; Araujo, J.P. On the Curie temperature dependency of the magnetocaloric effect. Appl. Phys. Lett. 2012, 100, 242407. [CrossRef] 